\title{
RONDOM DE MELANESISCHE "CARGO CULTS"
}

Een verschynsel dat sterk de aandacht heeft getrokken, reeds in de periode tussen de twee wereldoorlogen, en inzonderheid ook tydens de tweede, en daarná, zyn de zgn. "Cargo cults" in het Melan sische eilandengebied. Bestuursambtenaren en zendelingen constateerden in hun territoir bewegingen en uitbarstingen van deze culten, die $z y$, elk vanuit eigen gezichtspunt, met o gerustheid gadesloegen; de eersten, omdat zy daarin tegen het gouvernement gerichte onordelykheden bespeurden; de tweeden omdat zich enerzyds een wonderlyke vermenging van bybelse gedachten en overgeërfde inheemse voorstellingen vertoonde, die practisch neerkwam op een misverstaan van die bybelse boodschap, anderzyds de bewegingen niet zelden een rechtstreeks anti-christelyk karakter gingen aannemen. Naast deze direct geïnteresseerden waren het ook al spoedig de sociologen, ethnologen en godsdiensthistorici die belangstelling aan de dag legden voor deze merkwaardige bewegingen. Het gevolg was een brede stroom van litteratuur; een bibliografie over deze en verwante verschynselen, in 1952 verschenen, geeft reeds niet minder dan 152 nummers aan ${ }^{1}$, een aantal dat sedertdien met vele tientallen is vermeerderd.

Van een volledige beschryving van deze "cargo cults" moet in dit artikel wegens de beperkte ruimte worden afgezien; bovendien is dat al meermilen geschied. Een zeer leesbaar overzicht vindt men in het recente boek van Worsley ${ }^{2}$. Het is my te doen om enige opmerkingen van meer algemene aard rondom, en naar aanleiding van, deze culten.

37) E. JACOB, Theology ..., p. 171.

s8) Th. C. VRuezen, Hoofdlijnen, p. $154 \mathrm{v}$.

1) Bibliography of Cargo cults and other nativistic movements in the South Pacific, compiled by Ida Lusom. South Pacific Commission Technical paper no. 30 (Sydney), July, 1952 .

2) P. Worsley: The trumpet shall sound. A Study of "Cargo" cults in Melanesia, London, 1957. 
Wat de beschryving betreft, moge dus met een paar algemene aanduidingen worden volstaan.

De benaming ,cargo cults" is niet al te gelukkig. Er is lang niet altyd sprake van een cultus in de eigenlyke zin van het woord. Bovendien kan de samenstelling de indruk wekken alsof het gaat om een verering van de cargo, d.w.z. van de (materiële) goederen van de westerse cultuur. Dit nu is allerminst het geval; object van verering zyn niet deze goederen, maar de wezens die deze goederen schenken, de goden (event. God) en de voorouders. Zeker spelen de goederen een belangryke rol vanwege hun begerenswaardigheid, maar uiteindely $\mathrm{k}$ gaat het toch om iets anders, $\mathrm{nl}$. om datgene waarvan zy het symbool zyn: de heilstyd, die een tyd van overvloed wezen zal.

De achtergrond van de cargo-bewegingen (die in concreto de nodige verschillen vertonen, waarop wy nu niet kunnen ingaan) laat zich in het kort aldus schetsen: de inheemsen verbaasden zich over de rykdom en het technisch kunnen van de westerlingen. De enorme legervoorraden van de geallieëerden vooral tydens de laatste oorlog waren een onmiddellyke aanleiding tot de voorstelling dat de macht en het vermogen van deze vreemdelingen „,niet van deze wereld" waren. De Melanesiërs vonden dus de verklaring van deze wonderen in hun eigen mythische gedachtenwereld. De eerste indruk die men van de blanken had, vooral in de meer landinwaarts gelegen streken, waar men ze nog nooit eerder had gezien, was dat zy teruggekeerde doden geesten waren ${ }^{3}$, die uit zorg voor hun nabestaanden deze kwamen bezoeken om hun allerlei gaven te brengen. Naarmate men meer met de blanken in aanraking kwam, en ontdekte dat zy ook mensen waren, en naarmate men ook ontdekte dat deze mensen geenszins bereid bleken om hun overvloed met de inhe msen te delen, laat staan ze eenvoudig weg te schenken, veranderde de houding die men tegenover hen aannam. Een nieuwe verklaring voor hun rykdom werd gezocht en gevonden. Ofwel de god(en) der blanken was (waren) machtiger en vrygeviger dan de eigene; ofwel de blanken beschikten over betere middelen om (Zoals de Garia in N.O. New Guinea zeggen) de nanunanu (welwillende aandacht) van hun god tot zich te trekken; ofwel ze hadden op e.o.a. wyze de nananu van de inheemse goden ten eigen bate weten te winnen; ofwel de voorouders waren in het verre verleden naar het Westen gegaan omdat hun eigen volk niet naar hen luisterde, en hadden aan de westerlingen de kunst geleerd om allerlei wonderlyke zaken te maken, of de geheime formules waardoor zy de goden bewegen konden om hun deze te schenken. Op welke wyze ook voorgesteld (er zyn nog vele andere variaties, die soms tot hele verhalen zyn uitgedyd), de grondgedacht? is deze dat de cultuurgoederen rechtens en feitelyk niet aan de westerlingen toekomen, maar het eigendom (behoren te) zyn van de Melanesiërs.

3) P. Lawrence: Cargo cult and religious beliefs among the Garia, International Archives of Ethnography (Leiden), vol. XLVII, 1955, p. 11. Cf. R. M. BerNDT, A Cargo movement in the Eastern Central Highlands of New Guinea, Oceania (Sydney), vol. XXIII $(1952 / 53)$, p. 52,54 . 
En ze zullen ook eenmaal werkelyk aan de Melanesiërs komen, mits deze de machten (of ook: God, als de beweging christelyke elementen in zich opgenomen heeft) er op de rechte wyze om vragen en ze op de rechte wyze dienen. De gulden tyd, resp. de herstelde o rtyd, zal aanbreken wanneer het schip met cargo-in de binnelanden: vliegtuigenaankomt. Tal van profeten en visionairs zyn in de loop der jaren opgestaan, die in een droom of op andere wyze een openbaring zouden hebben gehad, waarin de aankomst van de cargo als een binnen enkele dagen te verwachten gebeurtenis werd aangekomdigd. Zulk een boodschap was dan herhaaldelyk aanleiding om als teken van geloof zich voor te bereiden door alle werk te staken, de tuinen te verwaarlozen, voedselvoorraden te vernietigen, varkens af te slachten, en onder zang en gebed het grote ogenblik af te wachten. ${ }^{4}$

Vry algemeen ziet men in de mythische voorstelling van de cargo en in de culten of althans bewegingen die daaraan ontsproten zyn, een reactie van een primitieve op de westerse cultuur. Dat in deze opvatting een goed stuk waarheid zit, tonen reeds de boven gegeven korte aanduidingen. De aanraking met de techniek der blanken en de produkten daarvan brengt de inheemse samenleving in een zekere crisis, waarin naast aanvankelyke vrees en eerbied ook bewondering, afgunst, een gevoel van tekort te komen enz. een rol spelen, en waarin men nu ,,vanwege de incompatibiliteit van verlangens en de middelen tot bevrediging daarvan, zyn toevlucht neemt tot imaginaire projecties", aldus byv. Firth ${ }^{5}$. Maar daarmede is nog niet zo heel veel gezegd. Op zyn minst komt toch de vraag op: vanwaar deze merkwaardige wyze van reageren, die zeker niet de enige mogelyke is en ook niet de meest voor de hand liggende? Guariglia ${ }^{6}$ noemt er enige die zich in heel andere richting be wegen. Men dient dus terdege te onderscheiden tussen de aanleiding die tot het ontstaan van deze bewegingen heeft geleid, en de oorzaken waaruit zy zyn ontstaan, beter nog: de grond waarin zy zyn geworteld. De aanleiding ligt zeer zeker in het contact met de westerse cultuur; de grond is niet te zoeken in min of meer toevallige invloeden van buitenaf, maar in de eigen cultuur, nader: in de religieuze voorstellingswereld, der inheemsen zelf.

In aansluiting hierby valt nog een andere opmerking te maken. De mythische voorstelling aangaande de wyze waarop de westerlingen aan de cargo gekomen zyn, kan de indruk maken van een mythenvorming ad hoc. En hoe sterker men de nadruk legt op de cargo cults en verwante bewegingen als reacties op de westerse cultuur en als crisissen, opgeroepen door de acculturatie, hoe gemakkelyker men uit het oog verliest, dat de wortels ervan veel dieper liggen. Er ontstaat dan eenzelfde eenzydigheid

4) Vgl. F. C. Kamma, De messiaanse Koréri-bewegingen in het Biaks-Noemfoorse cultuurgebied (diss.), Den Haag, 1954, p. 95 vv. (de "adventsnachten").

5) R. FIRTH, Social change in the Western Pacific, Journ. of the Royal Soc. of Arts, vol. 101, 803-819 (1953).

c) G. Guariglia, Numen V, 1958, p. 183. 
in de beoordeling als er byv. ten aanzien van de Ghost Dance ${ }^{7}$ onder de N. Amerikaanse Indianen lange tyd heeft geheerst, die men aanvankelyk te uitsluitend als reactieverschynsel tegen de „blanke" beschaving, en nauwelyks als een in de eigen cultuur der Indianen diep geworteld element begreep ${ }^{8}$. De cargo-mythen zyn niet uit de lucht komen vallen toen de Melanesiërs kennis maakten met europese en amerikaanse goederen; ze zyn wel aan deze nieuwe situatie geadapteerd. De voorstellingen van een heilstyd als een tyd van overvloed, van ,schatten" die door bemiddeling van de voorouders (dodengeesten) zullen komen, en die afkomstig zyn uit het Westen (waar het dodenryk ligt), zyn by vele Melanesische stammen heel oud, en behoren tot het traditionele geestelyke bezit. Wat nieuw is, dat is de toepassing van deze voorstellingen op de verschyning van de blanken in dit milieu en van hun goederen. Of misschien beter omgekeerd: het opnemen en inpassen van deze moderne verschynselen in de tradtionele mythische voorstellingen. De mythe wil immers rekenschap afleggen van alles wat zich voordoet, niet alleen van het oude, maar ook van het nieuwe. Ze is helemaal niet zo sta ' en onveranderlyk als men vaak wel denkt. Terwyl de kern dezelfde blyven kan, ondergaat de vorm vaak allerlei grotere of kleinere veranderingen in verband met nieuwe aspecten die zich voordoen. Een voorbeeld daarvan ziet men in de wyze waarop de allengs bekend wordende technische produkten van het Westen in de mythe hun weerspiegeling vinden: terwyl in die verwachting van de wederkomst van Manseren Manggoendi (de hoofdpersoon van de heilstrydverwachtingen in West-Nieuw Guinea) oorspronkelyk sprake is van een prauw, spreken latere versies resp. van een stoomboot, een motorschip, een vlieguig. ${ }^{9}$ En terwyl de ,schatten" die in de heilstyd aan de mensen ten deel zou den vallen, in vroeger tyd vooral verbonden waren met de hoog gewaardeerde pusaka's, zyn deze nu vervangen door stalen gereedschappen, europese kleding en gebruiksvoorwerpen, moderne wapens e.d. De vorm van de mythe blykt zich te wyzigen met de nieuwe gezichtspunten die binnen de horizon komen.

Zolang men in deze mythische gedachtensfeer blyft, is het niet verwonderlyk dat ook de middelen waardoor men de cargo hoopt te verkrygen, daardoor worden bepaald. Naar de omschryving van Lawrence: (the cargo cult) ,aims to acquire supplies of cargo for the natives by means of ritual ordained by the prophesies of certain inspired leaders". ${ }^{10}$ Telkens is weer gewezen op het naïeve, irrationele ens. van een dergelyke handelwyze, o.a. door Firth ${ }^{11}$. Het is niet geheel overbodig er op te wyzen dat dit zo moge zyn van uit óns gezichtspunt, maar dat het van uit het gezichtspunt van deze primitieve bevolking volkomen rationeel is. In de eerste plaats is er in dit milieu een zeer nauw verband tussen arbeid en ritueel. „Werk" (in dit gebied vooral tuinwerk) is nooit alleen maar

\footnotetext{
$\left.{ }^{7}\right)$ L. SPIER, The prophet dance, Menasha U.S.A., 1935; cf. Kamma, l.c. 211.

9) Kamma, l.c., p. 50.

10) Int. Arch. of Ethn., vol. XLVII (1955), p. 1.

11) Die spreekt van een "imperfect social and economic adjustment" (zie noot 5).
} 
werk on onze zin van het woord, maar omvat tevens allerlei magische handelingen waardoor $\mathrm{m} \mathrm{n}$ de toekomstige oogst zo overvloedig mogelyk tracht te doen $z \mathrm{yn}^{12}$. Het ene woord 'uap (als substantief: tuin, als verbum: werken in de tuin) sluit in Tangu zowel „labour" als ,,rite and chant" in zich ${ }^{13}$. In andere streken gebruikt men overeenkomstige termen, die ook deze dubbele betekenis hebben. En nu zyn het juist deze termen die óók gebruikt worden voor het cargo-ritueel ${ }^{14}$. In de tweede plaats is er de omstandigheid dat de Melanesiërs de westerse goederen nooit hadden zien maken, maar ze alleen in afgewerkte toestand zagen, en dat zy ook nooit een blanke hadden zien werken. Terwyl een inheemse enige dagen werken moest om byv. een byl uit de westerse voorraden te kunnen kopen, behoefde een blanke slechts een bon te schryven om te krygen wat hy hebben wilde, althans zo zág men het. En de conclusie was: de blanken hebben blykbaar een geheim ritueel waardoor zy zich hun cargo verschaffen; wie dat geheim ontdekt, zal dus ook de weg tot de cargo geopend vinden. Vandaar dat men graag bereid was ieders leider te volgen die beweerde dat hem dat geheim geopenbaard was ${ }^{15}$. Vandaar dus ook dat men meende deel aan de cargo te kunnen krygen alléén door een bepaald ritueel te volgen, waarby geen enkele poging werd gedaan om zelfs maar symbolisch de fabricage van europese goederen voor te stellen. W'at wel op verschillende plaatsen gebeurde, was het bouwen van voorraadhuizen waarin de cargo zou worden opgeborgen, alsook het brengen van stenen en stokken binnen die huizen, die, wanneer het langverwachte ogenblik zou aanbreken, op wonderlyke wyze veranderd zouden worden in goederen en wapens ${ }^{16}$.

Dat in een zo uitgestrekt gebied als Melanesië de culturele en religleuze achtergrond in de verschillende streken de nodige variaties vertoont, spreekt wel vanzelf. In kort bestek deze achtergrond samenvattend te schetsen, is dan ook niet mogelyk. $W_{y}^{\prime}$ beperken ons beter tot één bepaald gebied, om te illustreren hoe de cargo-bewegingen samenhangen met de traditionele religie. Wy kiezen daarvoor het gebied van de Garia, een volkje dat woont tussen de N.O. kust van Australisch Nieuw Guinea en het Bismarck gehergte, en adat door Lawrence intensief is onderzocht ${ }^{17}$.

Het karakteristieke van de cargo-beweging in deze omgeving laat zich in drie trekken samenvatten: (1) God is de bron van alle cargo; (2) de dodengeesten brengen de goederen uit het paradys naar de mensen; (3) het ritueel dient om God te bewegen, cargo te zenden, en de geesten er toe te brengen om de goederen af te leveren. De traditionele mythen en de daarop gegrondveste gebruiken leren ons het volgende: Toen de goden de wereld en de mensen (d.i. in eerste instantie het grondgebied

12) F. E. Williams, Orokaiva Magic, London, 1928.

13) K. L. O. BURruDGE, Cargo cult activity in Tangu, Oceania, vol. XXIV (1953/54), p. 247.

14) LaWReNCE, l.c., p. 15.

15) ibid., p. 14v.

16) BERNDT geeft daar in Oceania XXIII $(1952 / 53)$, p. 57, 59, 61, verschillende voorbeelden van.

17) Zie zyn meergenoemd artikel in Int. Arch. of Ethn. ,waaraan het volgende is ontleend. 
en het volk van de Garia) hadden gemaakt, leerden zy aan de eerste mensen het gebruik van de werktuigen die ze nodig hadden en van de riten die zy moesten uitoefenen. Daarby deelden zy ook hun „open” namen mede (d.w.z. de aan ieder bekende godennamen), waarmede men hen kon aanroepen, en tenslotte ook hun geheime namen, waardoor men zich van hun redewerking kon verzekeren. Alle traditionele kennis van de Garia berust op de mythen en op de overlevering van de geheime namen, waarvan iedere patrilineaire verwantschapsgroep een complete „,set" bezit, die men nodig heeft by de belangrykste bezigheden als tuinieren, jagen en varkens telen. Deze namen worden aan de jonge mannen bekend gemaakt by de initiatie, nadat zy door de onderhouding van allerlei tabus daarop zyn voorbereid. Immers men kan de wetenschap van deze machtige namen slechts verdragen, als men daartoe de nodige kracht heeft verzameld, en daartoe is niet iedereen in staat. De grote mannen by de Garia zyn zy, die door langdurige inachtneming van de strengste tabus in staat waren om álle geheime namen te leren; zy zyn dan ook de aangewezen leiders by alle belangryke ondernemingen. Zo zal het plantseizoen of de inwydingsceremonie niet kunnen plaats hebben zonder dat een van deze machtige mannen de geheime naam ,ademt", d.w.z. heel zacht voor zich uitspreekt en daardoor ,de nanunanu van de goden naar zich toetrekt". Het aldus uitspreken van de naam heeft dwingende kracht: de goden moeten er aan gehoorzamen; blyft het begeerde resultaat uit, dan ligt dat niet aan de goden, maar aan een fout by die magiër zelf.

Naast de goden zyn de dodengeesten machtige wezens van wier gezindheid veel afhangt. Zyn ze welgezind, dan zullen ze op allerlei wyze helpen by de tuinarbeid, de jacht enz.; ze zullen zelfs bereid zyn byv. sieraden by anderen te stelen en die aan hun nabestaanden geven, of de tuin van een vyand te laten verwoesten door wilde varkens e.d.m. Maar ze zullen dat alleen doen, wanneer men zyn verplichtingen nakomt, d.w.z. hun dezelfde eerbewyzen betoont die men ook verschuldigd is aan oudere of hoger in rang staande verwanten.- Het ritueel, zowel voor de goden als voor de dodengeesten, is betrekkelyk eenvoudig; dansen spelen daarby een belangryke rol, voorts trekt $\mathrm{m} n$ de aandacht van goden en geesten door het spelen op fluiten ${ }^{\mathbf{1 8}}$ en makk door gebed bekend wat men van hen wenst.

In deze godsdienst waarin de magie een grote plaats inneemt, blykt het vooral te gaan om het verkrygen van materiële goederen. De machten worden door de Garia vooral gebruikt om hun zaken in orde te houden. Alleen moet men zich hoeden deze ,materialistische" houding naar westerse maatstaf te beoordelen. Bezit en eigendom hebben in de primitieve gemeenschappen een andere betekenis dan by ons. Het brengt onmiddellyk tal van verplichtingen mee, waaraan men zich op geen manier

18) Ook elders vindt men dat; cf. K. E. Read, Nama cult of the Central Highlands in New Guinea, Oceania XXIII (1952/53), p. 5 vv.; BERNDT, ibid., p. 45. 
onttrekken kan; opstapeling van grote rykdom is feitelyk onmogelyk, men heeft de goederen voortdurend nodig in het dagelyks verkeer; er is een onafgebroken roulering, e.z. door de talryke feesten, waarby de „,rykaard" geschenken dient uit te delen, a.z. door by dergelyke gelegenheden uit prestige-overwegingen bezittingen te vernietigen. V rlangen naar rykdom is grotendeels verlangen om als feestgever de grand seigneur te kunnen spelen. ${ }^{19}$ Daarby komt dat, zoáls ook wel elders, ook in de Melanesische gemeenschappen relaties tussen mensen haast vanzelfsprekend hun uitdrukking vinden in het geven of uitwisselen van materiële goederen en voordelen. De hoger geplaatste gééft aan de lager geplaatste, $\mathbf{n}$ de laatste verricht in ruil daarvoor zyn diensten. En dat geldt niet slechts in het verkeer tussen de mensen, maar ook in dat tussen goden en mensen, en dodengeesten en mensen. En in al deze gevallen is dit verkeer de uitdrukking van nanunanu, van het ,denken aan-", het hebben van welwillende ,,aandacht" voor de andere party. ${ }^{20}$ Alleen wanneer dit er is, loopt alle verkeer, zowel in het horizontale als in het verticale vlak, glad.

Weerspiegelen de traditionele religieuze voorstellingen der Garia zich in de ideeën die achter de cargo cultus liggen, zy doen dat nie onveranderd. Tussen die beide in ligt $\mathrm{nl}$. als een factor van betekenis de christelyke zending, hier door de Luthersen gebracht, en na 1914 aanmerkelyke invloed op de bevolking verkrygend. Wat niet betekende dat men de bybelse boodschap zó begreep als de zendelingen bedoelden. Ziehier hoe de Garia de verhalen uit Genesis naar hun eigen mythologie interpreteerden. ${ }^{21}$ God schiep het paradys, het bos, de dieren en het voedsel. Hy zette Adam en Eva in het paradys, maakte cargo en gaf hun dat. Als straf voor hun cohabitatie verdreef God hen uit het paradys naar het bos (de wildernis), waar ze moesten leven zonder cargo. Zo leefden de mensen tot de tyd van Noach. Deze kreeg na de vloed vanwege zyn gehoorzaamheid opnieuw cargo; ook zyn zoons hadden toegang daartoe. Sem en Jafet gingen naar het land van de blanken en van Israël, en daar ze gehoorzaam bleven, gaf God hun ook steeds weer cargo. Maar Cham was brutaal tegen God, die hem daarom zyn recht op cargo ontnam. Hy kwam naar Nieuw Guinea en zyn nakomelingen hebben dank zy de ongehoorzaamheid van hun stamvader, nog altyd geen cargo. Maar nu is de zendeling gekomen met de leer van Jezus, die ook aan de zwarte mensen de rechte gehoorzaamheid aan God wil leren, opdat zy weer deel zo : den krygen aan de cargo, die God voor alle mensen heeft bedoeld. Het Christendom is dus de weg tot de cargo; door deze weg te volgen kan men de nanunanu van God verkrygen. Deze redenering die niet alleen in het Garia-gebied, maar ook op vele plaatsen elders in Nieuw Guinea en de omringende eilanden werd gevolgd, verklaart zowel de soms massale

19) Cf. P. Radin, Gott und Mensch in der primitiven Welt, Zürich, 1953. S.119 f.; 136 ff., 145 ff.; BerNDt, l.c. 45.

20) Lawrence, 1. l.c. p. 10.

21) ibid., p. 12 . 
bereidheid om het Christendom aan te nemen (in 1937 werd door inheemse evangelisten een grote doopplechtigheid gehouden in het Garialand, die gepaard ging met een publiekelyk afzweren van magische ceremoniën en het vernietigen van magische voorwerpen), alsook de teleurstelling en de afval die daarna weer te constateren viel, toen de cargo niet bleek te komen. Het verklaart ook dat ondanks christelyke elementen in mythe en rite, vele cargobewegingen allengs een min of meer uitgesproken antichristelyk karakter kregen, waarby de zendelingen beschuldigd werden van niet de gehele bybelse waarheid te hebben gebracht, maar juist het „geheim" van de cargo te hebben achtergehouden, of ook te hebben verzwegen dat de Messias uit de Papuas was ${ }^{22}$.

$W_{y}$ zien dus e.z. een voortleven van oude vormen, zowel in de mythe als in de rite, a.z. een beinvloeding van deze oude vormen door de van buitenaf gekomen cultuur, zowel materiëel (technische produkten) als geestelyk (de boodschap van de zending). Zoals reeds opgemerkt, wordt de cargo cult algemeen beschouwd als een crisisverschynsel, ontstaan door het op elkaar botsen van de primitieve en de westerse cultuurwereld; het is een aspect van het acculturatieproces. Nu ligt hierin nog één vraag waarop wy tenslotte moeten ingaan. Wanneer Guariglia in aansluiting aan onderzoekers als Linton, Herskovitz e.a. opmerkt ${ }^{23}$ dat ,der Kulturkontakt als Akkulturation eine der hauptsächlichen Quellen der Heilserwartungsbewegungen (ist)", dan heeft hy daarin in zekere mate gelyk; er dienen daarby echter twee reserves te worden gemaakt. In de eerste plaats dient te worden uitgemakt in hoeverre in elk bepaald geval autochthone voorstellingen van een gelukkige oertyd aanwezig zyn en in hoeverre deze een even autochthone voorstelling van een toekomstige heilstyd hebben bepaald-een element dat Guariglia zelf ook wel erkent. In de tweede plaats: wat verstaat men precies onder acculturatie? Het proces dat zich afspeelt in de ontmoeting van de moderne westerse cultuur met niet-westerse culturen? In het juist verschenen nummer van Wending ${ }^{25}$ haalt Locher ${ }^{26}$ met instemming een woord aan van de amerikaanse cultuuranthropoloog Kroeber: „In fact, in so far as history is more than the story of particular events and particular individuals and deals with social and cultural changes, a large part of all history the world over, possibly more than half of it, deals ultimately with the result of intercultural influencing-that is, acculturation".

22) Cf. Worster, Trumpet, p. 67, 118; Kamma, Koréri-bewegingen, 119, 139, 185. Hoe gernakkelyk de wederkomst van Christus ingepast werd in de eigen heilsver. wachtingen en in de cargo-beweging illustreren voorbeelden als gegeven door BERNDT, l.c. 137; WorsLeY, p. 111; Kamma, p. 132.

23) Numen $V(1958)$, p. 190.

24) Kamma, p. 192 vv., 222, slaat voor de amwankelyke Koréri-bewegingen de invloed van de contact-situaties niet hoog aan; vgl. in het algemeen, A. vaN DeURSEN, Der Heilbringer, Groningen, 1931, Zie ook Sierksma, Ned. Theol. Tydschr., XI, 417 vv.

25) Wending, Maandblad voor Evangelie en Cultuur (Den Haag), 14e jaarg., nr. 7 (Sept. 1959).

26) G. W. Locher, Het Westen en de niet-westerse wereld, ib., p. 379. 
Is het geoorloofd hierby niet alleen maar te denken byv. aan de inwerking van Hellas op Rome (zoals Locher doet), maar deze ,intercultural influencing" uit te breiden óók tot de wereld der primitieve culturen? My dunkt van wel. Naarmate het ethnologisch onderzoek dieper is doorgedrongen in deze culturen, is wel gebleken dat wy hier geenszins te doen hebben met een wereld waarin alles traditioneel vastligt, waarin alle instellingen gekarakteriseerd zyn door "permanence and immobility" en een afkeer van nieuwe ideeën. Al kennen deze volken geen ,historie” in onze zin van het woord, zy hebben natuurlyk een geschiedenis achter zich, en dat impliceert: contacten, verschuivingen, veranderingen. Op een bepaald gebied heeft Sierksma aangetoond hoe politieke verschuivingen ook religieuze gevolgen na zich slepen ${ }^{27}$.

In een interessant opstel over hun bevindingen in westelyk ZuidAustralië zegt R. en C. Berndt ${ }^{28}$ : de australische inboorling is van nature geinteresseerd in religieuze onderwerpen en speciaal in het christelyke ritueel. Dat brengt ,at ceremonial time" verschillende groepen byeen "for the exchange or showing of rites and the discussion of myth between the fully initiated" en hy ziet in dit interesse ook de verklaring van de verbreiding van religieuze ,wetten" en "dogmata" over enorme afstanden in dat woestyngebied.-Dat ook, afgezien van westerse invloed, in de primitieve wereld religieuze crisis-verschynselen kunnen optreden door infiltratie van ideeën van andere stammen, illustreert een eveneens uit Australië afkomstig voorbeeld. By enige Kimberley-stammen in N.W. Australië nam Petri een fatalistische verwachting waar van een voor de deur staande ondergang van het eigen volk en het sterven van het land door uitdroging. De oorzaak van dit fatalisme bleek te liggen in het feit dat van uit het Zuiden, uit de woestyn van Centraal-Australië, voortdurend nieuwe cultusvoorwerpen en riten, bezweringsformules, zangen en corrobori's, binnendringen, die alle een overwegend destructief magisch karakter dragen. De N.W. stammen noemen deze leringen en gebruiken Kurangara (,magisch gift") en de daarachter staande geesten, die men vreest als brengers van droogte, ziekte en dood, heten D'anba. Maar de in deze nieuwe cultus ingewyden beweren dat deze geesten juist overvloed van voedsel geven, en bovendien grote magische macht schenken over andere mensen. Hoe dit $\mathrm{zy}$, de voorvechters van deze cultus worden vooral onder de jongere generatie gevonden. De ouderen zien dit met ontsteltenis; niet zozeer uit bezwaren tegen het nieuwe, maar uit vrees dat de verwaarlozing van de eigen heilige gebruiken niet anders dan de zwaarste gevolgen met zich brengen kan. De verderfbrengende geesten van de woestynen in het binnenland, die toch al van ouds werden gevreesd, hebben bezit genomen van het stamgebied en zullen land en volk onvermydelyk ten onder doen gaan. Wy zien hier dus enerzyds een van

27) Ned. Theol. Tydschr. X, 209 vv.

28) A preliminary report of field work in the Ooldea region, West South Australia, Oceania XIII (1942/43), p. 56 noot. 
elders gekomen primitieve cultus die beslag legt op een volk, en de traditionele godsdienstige voorstellingen en gebruiken daarvan verdringt; anderzyds zien wy op grond van dit gebeuren een nieuwe eschatologie ontstaan onder hen die het met de nieuwe cultus niet eens zyn. Dat zyn geen verschynselen die zich alleen maar in de moderne tyd voordoen; ze zullen te allen tyde mogelyk zyn geweest. „Die Eingeborenen Kulturen der Gegenwart sind demnach nicht als konstante Grössen zu werten, sondern als Ergebnis einer langen geschichtlichen Entwicklung, in deren Verlauf gerade prophetische (en wy voegen toe: politische, kulturelle, u.a.). Bewegungen beträchtliche Modifizierungen hervorgerufen haben können" ${ }^{30}$.

H. W. ObBink

Utrecht,

1 September 1959. 